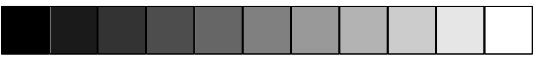

GEOUSP - Espaço e Tempo, São Paulo, No 16, pp. 159 - 162 , 2004 


\title{
NOTAS SOBRE O VI CONGRESSO BRASILEIRO DE GEÓGRAFOS
}

\author{
Hindenburgo Francisco Pires*
}

\section{I - O que foi e como foi o VI CBG}

O VI Congresso Brasileiro de Geógrafos (VI CBG), realizado no período de 18 a 23 de julho de 2004 pela Associação dos Geógrafos Brasileiros, na cidade de Goiânia, foi elaborado para comemorar os 70 anos da AGB.

A $68^{a}$ RGC (Reunião da Gestão Coletiva da AGB) de Julho de 2002, em Presidente Prudente, aprovou que o VI CBG fosse organizado, pela primeira vez, por quatro seções locais da AGB: Uberlândia, Catalão, Uberaba e Goiânia, cabendo a esta última seção local o papel de realização e implementação física do congresso.

Vários aspectos importantes do VI CBG merecem ser destacados:

1. O evento foi amplamente divulgado na internet e no Sítio da $A G B$, a repercussão do congresso em Goiânia foi extraordinária;

2. Esse evento representou um marco na capacidade de aglutinação e de mobilização dos geógrafos na América Latina, pelo número expressivo de inscritos, 3460 , e pelo número extraordinário de participantes, mais de 4200 , segundo a comissão organizadora do evento. Participaram também, o ministro das Cidades, os prefeitos de Goiânia e de Rio Claro - SP, além de representantes de entidades da Sociedade Civil, IBGE, CUT e MST;

3. A realização do congresso na Universidade Federal de Goiás não foi uma tarefa fácil, pois os servidores daquela instituição encontravamse em greve. Esta situação quase ameaçou a
Edição do Caderno de Resumos do VI CBG. Para a sua realização e a Edição de seu Caderno de Resumos foi necessária uma negociação com o Comando de greve dos funcionários da UFGO;

4. Foi também disponibilizada a produção científica no Sítio da $A G B$, prática que vem se consolidando nos seus últimos Encontros; esse acervo cresce dia a dia. Aliás, desde o "Fala Professor", de Curitiba em 1999, que esta iniciativa foi implementada, mas foi no "XIII Encontro Nacional de Geógrafos - XIII ENG", em João Pessoa, realizado em 2002, que este trabalho teve repercussão internacional, com a transmissão on-line da Conferência de Horácio Capel;

5. Foi votado e aprovado que o XIV Encontro Nacional de Geógrafos será realizado em Rio Branco, em 2006. A escolha de Rio Branco gerou um grande "frisson" pelos que estavam contra a realização deste evento na região norte do país, devido à ausência de uma seção local da AGB nesta municipalidade, à distância e aos custos com deslocamento. Os que estavam favoráveis, além de proporem a criação de uma seção local da AGB no Rio Branco, justificaram que o último ENG na região norte ocorreu em Belém, em 1976, portanto há mais de 28 anos (Cf. Quadro - Datas de realização de Eventos da AGB abaixo).

Os ENGs e CBGs promovidos pela $A G B$ cronologicamente ocorreram nas seguintes cidades: 
Datas de realização de Eventos da AGB

\begin{tabular}{|c|c|c|}
\hline Ano & Municipalidade & Região \\
\hline $1944^{*}$ & São Paulo & Sudeste \\
\hline $1954^{*}$ & Ribeirão Preto & Sudeste \\
\hline 1972 & Presidente Prudente & Sudeste \\
\hline $1974^{*}$ & Belo Horizonte & Sudeste \\
\hline 1976 & Belém & Norte \\
\hline 1978 & Fortaleza & Nordeste \\
\hline 1980 & Rio de Janeiro & Sudeste \\
\hline 1982 & Porto Alegre & Sul \\
\hline $1984^{*}$ & São Paulo & Sudeste \\
\hline 1986 & Campo Grande & Oeste \\
\hline 1988 & Maceió & Nordeste \\
\hline 1990 & Salvador & Nordeste \\
\hline 1992 & Presidente Prudente & Sudeste \\
\hline $1994^{*}$ & Curitiba & Sudeste \\
\hline 1996 & Recife & Nordeste \\
\hline 1998 & Vitória da Conquista & Nordeste \\
\hline 2000 & Florianópolis & Sul \\
\hline 2002 & João Pessoa & Nordeste \\
\hline $2004^{*}$ & Goiânia & Oeste \\
\hline 2006 & Rio Branco & Norte \\
\hline
\end{tabular}

Obs: * Data de realização dos CBGs.

Como podemos observar no quadro acima, a maioria dos eventos da AGB (42\%) ocorreu na região sudeste, logo em seguida veio o nordeste com $31 \%$ das realizações;

6. Outro ponto polêmico foi a votação da reformulação do Estatuto da AGB na Assembléia Extraordinária Estatuinte. Embora houvesse uma proposta que apontava para transformar a AGB em uma organização profissional de fins públicos, capacitada a oferecer: cursos; pesquisas; relatórios de impactos ambientais; planejamento urbano e rural; consultoria, esta proposta não foi aprovada, continuando a AGB uma entidade híbrida, composta de profissionais, professores e estudantes de Geografia. Esta decisão fez com que a AGB continuasse como uma entidade fraca, de reduzida participação nas questões de políticas públicas, dependente de recursos dos associados;

7. Como de costume a AGB elegeu a nova diretoria para o biênio de 2004-2006, só que desta vez houve um embate entre duas chapas, como em 1988. A chapa vencedora possui a maioria de seus componentes oriundos do Rio de Janeiro. Parabenizamos a nossa nova diretoria, liderada pelo geógrafo Jorge Luiz Borges, e esperamos que leve a frente uma proposta de consolidação da nossa entidade numa perspectiva mais profissional e engajada com as questões de interesse político-social.

\section{II - Os 70 anos da AGB}

Para comemorar e resgatar os 70 anos da AGB, foi preparado uma edição especial da Terra Livre - Número 22, que teve como tema 
central: "AGB 70 anos: Trajetórias e Contribuições". Esta edição possui 18 artigos com depoimentos que ajudam a fortalecer a identidade histórica e o caráter cultural de nossa entidade.

Durante o congresso foi apresentada também a mostra Caio Prado Junior, contendo um acervo de fotos e cópias de documentos alusivos à criação da AGB como, por exemplo, a ata de sua fundação, de 17 de Setembro de 1934.

Pode-se afirmar que a organização dos eventos da AGB vem se profissionalizando, embora esta forma de organização seja criticada devido à terceirização dos serviços, mas mesmo sem a edicão de um caderno com o guia de programação, que por razões de ordem econômica não foi publicado, não se pode negar que houve uma eficiente condução das inscrições e orientação das atividades que envolveram um público tão grande.

Cumpre também destacar que houve uma preocupação em subsidiar e baratear os custos de alimentação e alojamento para os estudantes de todas as regiões do Brasil.

\section{III - O Tema do Congresso e os Eixos Temáticos}

O tema aprovado para realização do VI CBG foi: Setenta Anos da AGB: As Transformações no Espaço e a Geografia do Século XXI, distribuído em cinco eixos temáticos.

Nos cinco dias do evento, a produção científica do VI CBG impressionou também pelos seus números: o Caderno de Resumos reuniu mais de 2000 trabalhos; 55 minicursos ministrados; 26 mesas redondas e 27 comunicações coordenadas realizadas.

A publicação de artigos em formato de CDROM seguiu a trajetória inicialmente implementada em João Pessoa, mas, desta vez, coroada com a publicação de todos os textos expandidos.

Sobre a implementação desses cinco eixos temáticos devem ser destacados três importantes iniciativas:
1. A introdução do Eixo I: "Espaço Agrário e Espaço Urbano: abordagens atuais" representou um esforço de ruptura da trajetória hegemônica que consagrou esta temática como objeto de estudo e debate apenas da Economia Rural e da Sociologia Rural, deve-se ressaltar que esta iniciativa pioneira logrou o êxito de por na ordem do dia está temática dentro do escopo de reflexão e análise da Geografia;

2. A reabertura do diálogo e o debate entre a AGB e o IBGE, motivada pela temática "O IBGE e a Geografia", no Eixo IV: Ensino, Formação e Exercício Profissional. Desde o final dos anos 70, quando a AGB permitiu a participação do movimento estudantil nos seus fóruns, houve um distanciamento dessas duas instituições que, nesse evento, buscaram o debate político e democrático, num esforço de integrar e articular perspectivas;

3. Foi significativo o esforço para refletir o Tema do Congresso: "as Transformações no Espaço e a Geografia do Século XXI", embora essa tentativa tenha sido prejudicada por não se ter contemplado o debate sobre os impactos e as transformações produzidas pelo desenvolvimento das Tecnologias de Informação e Comunicações no território e na sociedade. Lamentavemente, o ciberespaço e a internet foram temas negligenciados, embora essa temática já esteja incluída na maioria dos fóruns da Geografia em outros países.

\section{IV - Saldos e Legados}

A Contribuição do VI CBG na formulação de propostas de políticas de desenvolvimento territorial para o Brasil foi inviabilizada, uma vez que houve um fraco engajamento da $A G B$ em discussões sobre a Reforma Universitária, sobre a política econômica do governo Lula e sobre a excessiva interferência das instituições multilaterais na formulação da política econômica do Brasil.

Faltou a compreensão de que a Geografia precisa ser não apenas coadjuvante dos movimentos sociais, mas precisa ser protagonista na formulação e na elaboração de projetos de políticas de desenvolvimento territorial para o Brasil. 


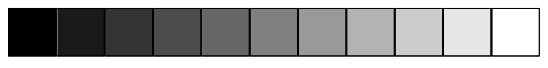

A conferência de abertura de Arlete Moysés Rodrigues vai ao encontro dessa reflexão, quando argumenta:

"O fetiche das relações entre as coisas que oculta as relações entre os sujeitos cria uma série de deslocamentos nos discursos dominantes, que muitas vezes nos envolvem até pela necessidade de "reconhecimento" de nossa importância."

A Conferência de Encerramento do VI CBG de Dirce Suertegaray denunciou a subsunção do discurso da Geografia à lógica da acumulação, e destacou a necessidade de se pensar o presente numa perspectiva mais ativa, quando propõe:
"A tarefa mais recente da Geografia é geografar, na perspectiva da mudança social, da transformação de um mundo onde o cidadão é um mero consumidor, para um mundo, onde o processo de construção da cidadania seja condição de um geografar coletivo. Geografar, portanto, não é só uma tarefa de geógrafos, é uma tarefa ampla que necessita ser espraiada no corpo social. Este espraiamento é, sem dúvida, parte de nossa tarefa enquanto profissionais da Geografia, sejamos nós, professores ou bacharéis. É tarefa da nossa associação a partir de nós."

Precisamos, portanto, consolidar como prática nos Encontros, Congressos e tantas "Falas" da AGB a necessidade de transformar a Geografia em uma ciência que protagoniza sua história sem proto-agonizar suas desesperanças. 